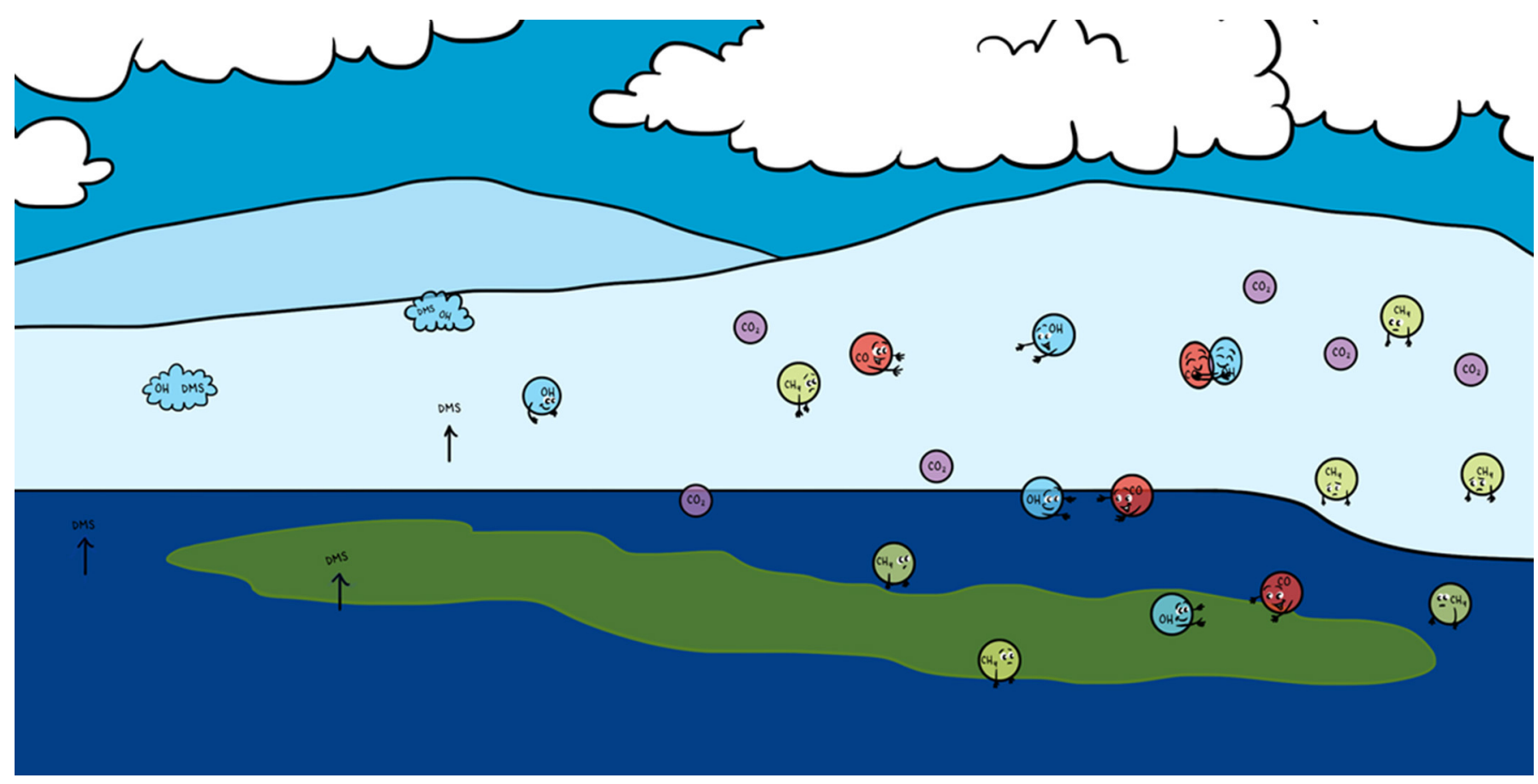

\title{
TINY BUT POWERFUL: HOW TINY AMOUNTS OF CERTAIN GASES CAN MAKE A BIG DIFFERENCE IN THE EARTH'S CLIMATE
}

\section{Hanna Campen * and Hermann W. Bange}

GEOMAR Helmholtz Center for Ocean Research Kiel, Kiel, Germany

YOUNG REVIEWERS:

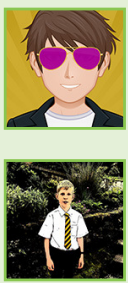

FINN

AGE: 11

RUARI

AGE: 12
Comparable to carbon dioxide, dimethyl sulfide (DMS), and carbon monoxide (CO) are tiny gases that have a great impact on our climate. Though occurring only in very small amounts in the atmosphere they are climate influencers, especially in the Arctic. The Arctic is a unique place on Earth where all life is adapted to the extreme cold. Therefore, global warming is a great threat to the Arctic. DMS and CO are produced in the Arctic Ocean and can go into the atmosphere. There, $\mathrm{CO}$ may enhance the warming of the Arctic. On the other hand, DMS possibly cools the atmosphere because it helps forming clouds. The processes CO and DMS are involved in, are complex and will probably alter under a changing climate. It is important to understand these processes to get an idea of the future Arctic Ocean and climate to find ways to save the Arctic. 
TRACE GASES

Gases that make up together $<1 \%$ of our atmosphere (Figure 1).

\section{ARCTIC OCEAN}

The Arctic Ocean includes the North Pole region and is surrounded by northern parts of Europe and Asia and North America. It is the coldest, smallest and shallowest ocean compared to the Pacific, Atlantic, Indian, and Southern Oceans. Polar bears live in the Arctic region but there are no penguins.

\section{CARBON \\ MONOXIDE}

A less known trace gas that has the potential to enhance global warming.

\section{DIMETHYL SULFIDE}

A gas that possibly cools the atmosphere by helping to form clouds.

\section{GREENHOUSE} EFFECT

The burning of oil and gas releases certain trace gases. Some of those gases are acting as greenhouse gases and accumulate in the atmosphere of the Earth. Like a greenhouse, they keep more warmth of the sunlight in the atmosphere, which leads to global warming.

\section{TINY GASES MAKE A DIFFERENCE!}

That sounds funny at first glance but, looking more closely, this is not only true when we are in an elevator realizing someone had beans for lunch. It is also true for so-called trace gases. Trace gases occur in our atmosphere in very small amounts. But do not be fooled: they influence Earth's climate in a big way, namely through their behaviors and interactions. This is especially true in the Arctic Ocean, one of the most impressive, yet vulnerable, places on Earth. You have probably heard of carbon dioxide, since it is one of the key drivers for climate change-the star influencer among trace gases. But have you heard of carbon monoxide and dimethyl sulfide? They are further influencers-trace gases whose forces we should not overlook. Here comes their story. Where do they come from? How powerful are they and will they influence the future of the Arctic? On Instagram, we follow influencers and let them affect our behavior. Why do not we take trace gases as an inspiring example, too? Even though we may feel tiny when facing this overwhelming climate problem, our individual behavior makes a difference!

\section{WHAT DO WE MEAN BY TINY?}

As the name trace gases indicates, these gases only occur in the air in very small (trace) amounts. You may already know that the air we breathe consists mainly of nitrogen and oxygen, so these are not considered trace gases. All trace gases together make up $<1 \%$ of the atmosphere. Carbon monoxide and dimethyl sulfide are only two of several trace gases, thus they represent an even tinier fraction (Figure 1). We might conclude that a small fraction means a small impact; so we may think that trace gases are not very important. However, this is not true at all! Carbon dioxide $\left(\mathrm{CO}_{2}\right)$ is a trace gas, too. Its properties, in combination with its increasing concentration in the atmosphere, keep the warmth of sunlight trapped close to the Earth longer, so that the Earth warms up. This is similar to the way a greenhouse allows tomatoes to grow, even in wintertime, so we call it the greenhouse effect. The greenhouse effect is so strong that it influences the entire world's climate. But what about carbon monoxide and dimethyl sulfide? In the rest of this article, we will explain the influence of these important trace gases on the Earth's climate.

\section{WHAT IS CARBON MONOXIDE AND WHERE IS IT FOUND?}

\section{\#Climateinfluencer \#Indirectgreenhousegas \#Oceanproduct \#Interactionlover}

Carbon monoxide (CO) mainly occurs where things are burning. You may have heard that $\mathrm{CO}$ is a dangerous gas that can be poisonous at certain levels. Most $\mathrm{CO}$ comes from the burning of 
Figure 1

All trace gases together make up $<1 \%$ of the atmosphere. Carbon monoxide $(\mathrm{CO})$ is one of these trace gases. Picture the atmosphere as an Olympic-size swimming pool. Also picture an ordinary drinking glass filled with ink. Pour this glass of ink into the pool and watch how much it dilutes in the water. That equals approximately the amount of $\mathrm{CO}$ in the atmosphere ${ }^{1}$

1 Volume of an Olympic-size swimming pool: 50 $\times 25 \times 2 \mathrm{~m}=2,500$ $\mathrm{m}^{3}=2,500,000$ liters. Fraction of $\mathrm{CO}$ in the atmosphere: $10^{-7}=0.0000001$. Volume of ink required to obtain the same fraction in the pool: 0.0000001 $\times 2,500,000$ liters $=$ 0.25 liters, i.e., an ordinary drinking glass $(250 \mathrm{~mL})$ filled with ink.

\section{PHYTOPLANKTON}

Tiny, floating marine algae that are the base of all life in the ocean.

\section{CO in the atmosphere...}

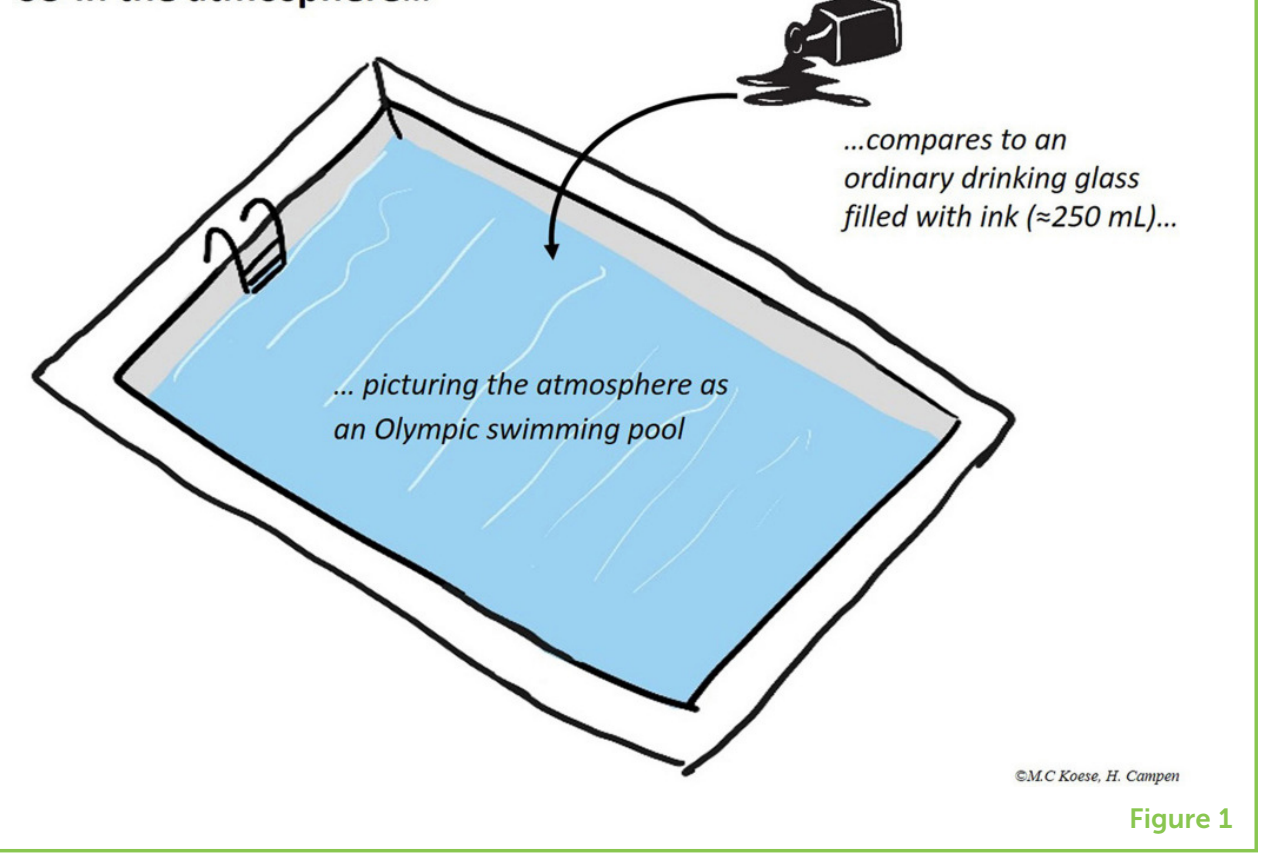

fuels, such as petrol. However, scientists found out that the ocean contains a lot of $\mathrm{CO}$, too. In the ocean, floating dead plant material and tiny marine algae, called phytoplankton, react with sunlight to produce $\mathrm{CO}$ [1]. The amounts of $\mathrm{CO}$ produced at certain areas of the ocean's surface can become so large that it goes into the atmosphere. That is why scientists call the ocean a source of atmospheric $\mathrm{CO}-\#$ oceanproduct.

How does $\mathrm{CO}$ behave in the atmosphere? As you can see from Figure 2, $\mathrm{CO}$ is a simple molecule. It consists only of one carbon and one oxygen atom. However, because of its properties, it likes interacting and reacting with other molecules in the air. That is what characterizes its influence -\#interactionlover. Once $\mathrm{CO}$ is released into the air, its favorite reaction partners are hydroxyl molecules $(\mathrm{OH} \cdot)$. This means that $\mathrm{OH}$. is CO's best friend and they love to interact with each other. In their interaction, $\mathrm{CO}$ rapidly takes up the oxygen atom of $\mathrm{OH}$. Hence, that gives $\mathrm{CO}+\mathrm{O}$. Any idea what that forms? Exactly: $\mathrm{CO}_{2}-\mathrm{a}$ greenhouse gas.

$\mathrm{OH}$. molecules are often called the cleanser of the atmosphere, because $\mathrm{OH}$. can react with and destroy many atmospheric compounds, including some dangerous ones. For example, $\mathrm{OH}$. also reacts with methane $\left(\mathrm{CH}_{4}\right)$, another trace gas and a powerful greenhouse gas like $\mathrm{CO}_{2}$. When $\mathrm{OH}$. reacts with $\mathrm{CH}_{4}$, the danger of $\mathrm{CH}_{4}$ is invalidated. However, $\mathrm{OH}$. likes reacting with $\mathrm{CO}$ much more. Thus, if $\mathrm{CO}$ is present, it takes away $\mathrm{OH}$., the potential reaction partner of $\mathrm{CH}_{4}$, and prolongs the time $\mathrm{CH}_{4}$ stays in the atmosphere [2]. That enhances the harmful warming effect of $\mathrm{CH}_{4}$ on the atmosphere. So, $\mathrm{CO}$ causes a chain reaction that in turn leads to warming. That 
Figure 2

(A) Carbon monoxide (CO) and (B) dimethyl sulfide (DMS). CO consists of one carbon (pink) and one oxygen (blue) atom bonded to each other. DMS consists of two methyl groups (pink and green) connected by a sulfur atom (yellow) in its center. A methyl group is one carbon atom binding three hydrogen atoms.

CLOUD

CONDENSATION NUCLEUS

A particle in the air that acts like a seed for cloud formation. Around it a cloud can grow.
A

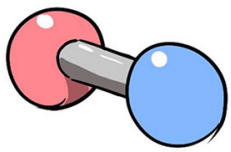

$\mathrm{CO}$
B

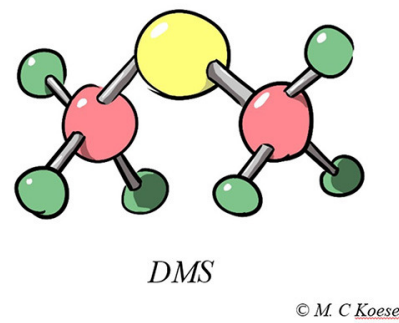

is why $\mathrm{CO}$ is called an \#indirect greenhouse gas-an influencer of the climate.

At this point, it may be clearer to you why we care how much $\mathrm{CO}$ is produced in remote oceanic areas, such as the Arctic Ocean. The Arctic Ocean is less influenced by land-produced CO than many other areas of the world, simply because the surrounding land is not so densely populated. The release of $\mathrm{CO}$ from the Arctic Ocean into the atmosphere could make a difference for the Arctic climate. Does this mean there is no good news for the Arctic Ocean? The question is, are there other influencer molecules that might counteract the effect of the $\mathrm{CO}$ that is released from the ocean? Now DMS comes into play.

\section{WHAT IS DIMETHYL SULFIDE AND WHERE IS IT FOUND?}

\section{\#climateinfluencer \#biologicalproduct}

Dimethyl sulfide (DMS) is a simple molecule, too. It consists of two methyl groups at its ends and one sulfur atom in its center-\#sulfurcontainer. A methyl group is a carbon atom binding three hydrogen atoms. However, the sulfur atom makes the molecule special: sulfur is needed for all living organisms to build proteins and other key components of their cells. In the ocean, DMS is produced by phytoplankton and bacteria [3]-\#biologicalproduct. Hence, through DMS production, sulfur becomes available to other organisms. However, like CO, DMS can be released from the ocean into the atmosphere. And there, its sulfur plays another central role!

When released into the atmosphere, DMS can help to create clouds. Once DMS is in the air, it also reacts with $\mathrm{OH}$. and makes cloud-forming particles called cloud condensation nuclei. You can picture a cloud condensation nucleus (CCN) as a very small particle that acts like a seed-a seed for a cloud that will grow around it-\#cloudcreater. You have probably noticed that the more clouds there are in the sky, the less sunlight reaches us on the ground. The clouds reflect the sunlight back to space, and less sunlight at 
Figure 3

All trace gases together make up $<1 \%$ of the atmosphere. $\mathrm{CO}$ and DMS are two of these trace gases. DMS can help to create clouds, which could potentially lead to a cooling of the atmosphere. CO could further warm the atmosphere because it promotes the formation of further greenhouse gases, such as $\mathrm{CO}_{2}$, and prolongs the lifetime of $\mathrm{CH}_{4}$ in the atmosphere. So, it is difficult to predict what the overall influence of trace gases on the Arctic climate will be in the future.

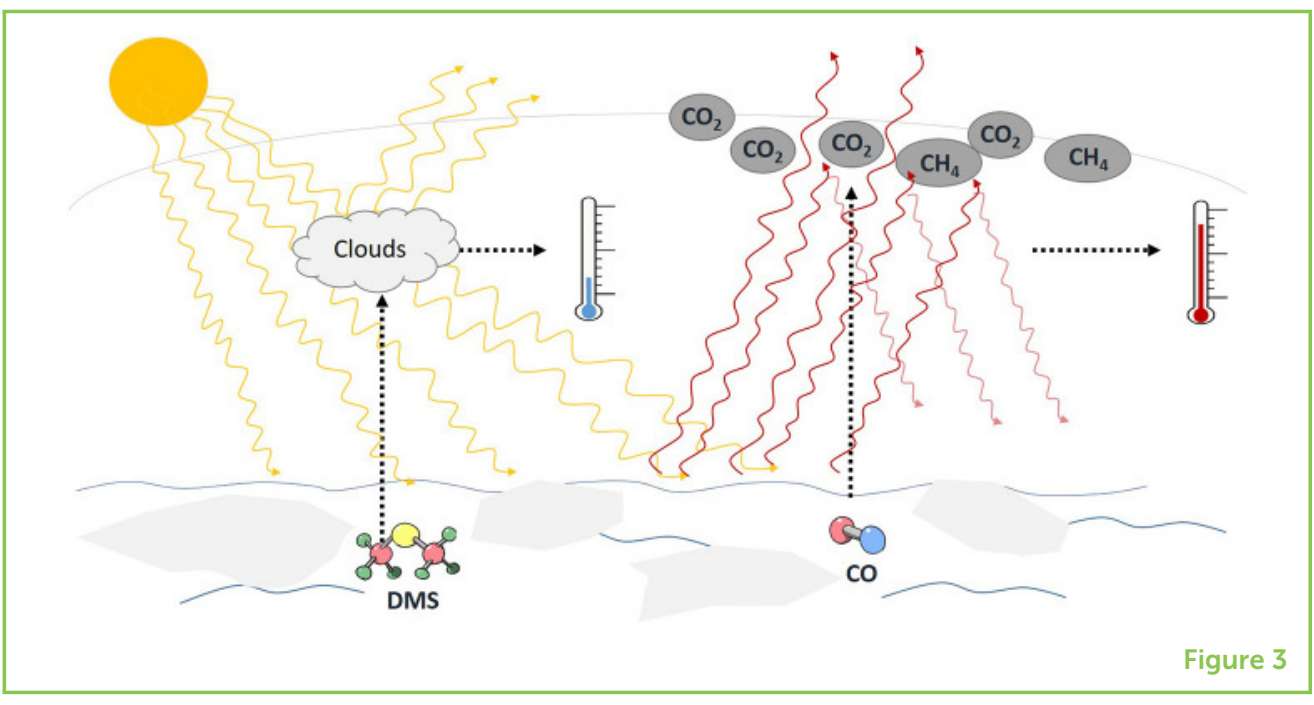

the Earth's surface means the surface gets cooler. Scientists call this cloud formation theory the CLAW hypothesis, which is summarized as follows: marine phytoplankton can cool the Earth by producing DMS, and consequently, clouds [4] -\#climateinfluencer. It is crucial that we find out if the CLAW theory is true for remote areas, like the Arctic Ocean, which are especially threatened by warming. That is why we want to study DMS production and all related processes very carefully in the Arctic Ocean.

\section{WHY IS THE ARCTIC OCEAN SO IMPORTANT?}

Cooler areas of the Earth can warm faster than areas that are already relatively warm. Scientists have seen that the Arctic region, therefore, is warming much faster than other regions of the world. This is important because the Arctic region plays an important role in global weather and climate. The Gulf Stream is a good example of the Arctic's influence. The Gulf Stream is an ocean current that brings warmth from the tropics to Europe and is thus responsible for the mild climate in Europe. The Gulf Stream's main driving force is seawater from the Arctic, which is very cold and salty. Cold, salty seawater is so heavy and dense that it sinks down to the ocean bottom, resulting in major water movement, kind of like a pump. Now imagine that the Arctic Ocean's temperature and salt content change. The melting of Arctic ice due to the ongoing warming of the Arctic will add loads of fresh water, which contains less salt than seawater. This warmer, fresher water will not sink like cold, salty water, and this change could weaken the Gulf Stream. Changes to the Gulf Stream would not only affect the Arctic itself, but could have consequences for other places in the world too, such as Europe.

So, you can see that it makes sense to investigate the many consequences of climate change in the Arctic, to learn from them, and to determine how these changes might affect other areas of Earth. Moreover, we need this information to predict how weather and 
climate will behave in the future-how our world will look when you are 90 . By predicting the future climate, we can hopefully find ways to adapt to the changes or even find solutions to stop them.

\section{HOW WILL CO AND DMS INFLUENCE THE FUTURE OF THE ARCTIC OCEAN AND OUR CLIMATE?}

We all know that the Earth is getting warmer, especially the Arctic Ocean. Thinking of the interactions we have just discussed, the picture becomes clear: environmental changes like climate warming and melting ice can affect the production and release of $\mathrm{CO}$ and DMS in the Arctic Ocean $[5,6]$. However, we also saw how complex the production and release processes of DMS and CO are. That is why we are uncertain whether $\mathrm{CO}$ and DMS in the Arctic Ocean will become more or less abundant and, in turn, whether that would cool or further warm the Arctic atmosphere (Figure 3).

Finally, we explained that what happens in the Arctic Ocean does not necessarily stay in the Arctic Ocean, but these changes can affect the rest of the world's climate. Therefore, it is extremely important to continue to investigate the behavior of climate-relevant trace gases like $\mathrm{CO}$ and DMS in the Arctic, under different future scenarios. Even though trace gases occur in tiny amounts, they still make a big difference.

\section{ACKNOWLEDGMENTS}

We thank Mehmet C. Köse for providing Figures 1, 2. This work is a contribution to the PETRA project (FKZ 03F0808A) which was funded by UKRI-NERC and BMBF as part of the Changing Arctic Ocean programme.

\section{REFERENCES}

1. Stubbins, A., Uher, G., Law, C. S., Mopper, K., Robinson, C., Upstill-Goddard, R. C. 2006. Open-ocean carbon monoxide photoproduction. Deep Sea Res. II Top. Stud. Oceanogr. 53:1695-705. doi: 10.1016/j.dsr2.2006.05.011

2. Conte, L., Szopa, S., Séférian, R., and Bopp, L. 2019. The oceanic cycle of carbon monoxide and its emissions to the atmosphere. Biogeosciences 16:881-902. doi: 10.5194/bg-16-881-2019

3. Lovelock, J. E., Maggs, R. J., and Rasmussen, R. A. 1972. Atmospheric dimethyl sulfide and the natural sulfur cycle. Nature 237:452-3.

4. Charlson, R. J, Lovelock, J. E., Andreae, M. O., and Warren, S. G. 1987. Oceanic phytoplankton, atmospheric sulfur, cloud albedo and climate. Nature 326:655-61.

5. Levasseur, M. 2013. Impact of Arctic meltdown on the microbial cycling of sulfur. Nat. Geosci. 6:691-700. doi: 10.1038/ngeo1910 
6. Tran, S., Bonsang, B., Gros, V., Peeken, I., Sarda-Esteve, R., Bernhardt, A., et al. 2013. A survey of carbon monoxide and non-methane hydrocarbons in the Arctic Ocean during summer 2010. Biogeosciences 10:1909-35. doi: 10.5194/ bg-10-1909-2013

SUBMITTED: 30 November 2019; ACCEPTED: 21 January 2021; PUBLISHED ONLINE: 18 February 2021.

EDITED BY: Kirsty C. Crocket, University of Edinburgh, United Kingdom

CITATION: Campen H and Bange HW (2021) Tiny But Powerful: How Tiny Amounts of Certain Gases Can Make a Big Difference in the Earth's Climate. Front. Young Minds 9:516417. doi: 10.3389/frym.2021.516417

CONFLICT OF INTEREST: The authors declare that the research was conducted in the absence of any commercial or financial relationships that could be construed as a potential conflict of interest.

COPYRIGHT @ 2021 Campen and Bange. This is an open-access article distributed under the terms of the Creative Commons Attribution License (CC BY). The use, distribution or reproduction in other forums is permitted, provided the original author(s) and the copyright owner(s) are credited and that the original publication in this journal is cited, in accordance with accepted academic practice. No use, distribution or reproduction is permitted which does not comply with these terms.

\section{YOUNG REVIEWERS}
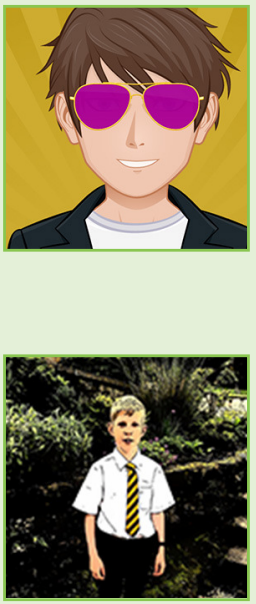

\section{FINN, AGE: 11}

My name is Finn and I am 11 years old. My hobbies are running, reading (including this paper!), drawing, football, cooking, and sleeping! I also love swimming, which is really fun, especially butterfly. We go on many holidays together as a family and my favorite ones so far were going to Japan and hiking from hut to hut in the Pyrenees. At school, I like maths the most and in my opinion, it is the easiest subject.

\section{RUARI, AGE: 12}

Ruari loves science, particularly anything related to space! He hopes to be an astronaut 1 day and really wants to travel to Mars. He loves reading adventure books, doing back-flips on his trampoline and playing the pipes, when not at school.

\section{AUTHORS}

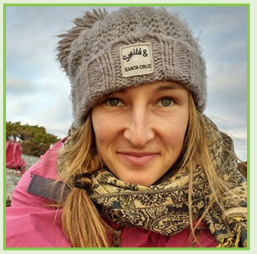

\section{HANNA CAMPEN}

Hanna Campen looks on how certain gases occurring only in tiny amounts in the atmosphere influence climate. She investigates how that will evolve in a future changing Arctic Ocean. She studied biology and biological oceanography in Kiel, Germany. Now she is doing her Ph.D. at the GEOMAR Helmholtz Centre for Ocean Research Kiel. She is passionate about seeing nature as our home and therefore protecting it. She thinks that talking about climate change and its consequences 


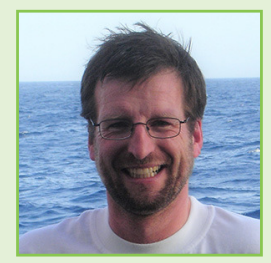

with as many people as possible eventually helps to change how we treat our only planet. *hcampen ageomar.de

\section{HERMANN W. BANGE}

Hermann Bange studied chemistry in Göttingen and Freiburg. He is now working as a marine biogeochemist at the GEOMAR Helmholtz Centre for Ocean Research in Kiel, Germany. He is an expert for measuring climate-relevant gases, such as nitrous oxide, methane, carbon monoxide, and dimethyl sulfide. Since the time of his Ph.D. he is fascinated by the fact that tiny gases with very low abundances in both the oceans and the atmosphere can make a huge impact on the Earth's climate. 